\title{
Inequality of healthy life expectancy for the Chinese elderly and its trend
}

\author{
Kaishan Jiao
}

\author{
Correspondence: jks0706@126.com \\ Department of Sociology, Minzu \\ University of China, No. 27, \\ Zhongguancun South Street, \\ Haidian District, Beijing, China
}

\begin{abstract}
In this study, we use long-term follow-up survey data to explore the inequality of the healthy life expectancy among the elderly and the trends of such expectancy among different birth cohorts and at different ages. The results show that older people with higher socioeconomic status do not have a significant advantage in healthy life expectancy. Its advantage in life expectancy is mainly due to the relatively low mortality rate under conditions of disability, i.e., the relatively long life expectancy with disability. This also shows that the elderly with higher socioeconomic status is at the stage of disability expansion. In addition, the study examines the age effect and cohort effect of health inequality and points out that health inequalities among different socioeconomic status groups are likely to increase in the future.
\end{abstract}

Keywords: Chinese Elderly, Life expectancy, Healthy life expectancy, Inequality

\section{Introduction}

Along with the transition of the human disease spectrum from acute and infectious diseases with high mortality to chronic diseases with low mortality (Fries 1983) has come the drastic increasing of life expectancies worldwide and the critical issue of whether increased life spans are "healthy" life spans or not-in other words, whether the increasing of life expectancies indicates the improvement of the overall health of populations or not. If the increasing portions of life were periods spent under unhealthy conditions or suffering from diseases, given the significant population growth of the elderly, ${ }^{1}$ greater life expectancies would result in heavier burdens on social health services and the economic cost of disease. Therefore, in addition to life expectancy, the quality of life-i.e., healthy life expectancy-should be taken into account during the discussion of population health conditions and health service policymaking. Since the 1970s, the healthy life expectancy, which is a comprehensive measurement of life span and quality, has received attention and concern from the World Health Organization (WHO), national health departments and scholars. Compared with the life expectancy index, the healthy life expectancy not only captures the mortality rate, but also takes into account health conditions at certain ages, which is thus a powerful

\footnotetext{
${ }^{1}$ A sample survey of $1 \%$ of the national population in 2015 showed that China has 222 million people over 60, constituting $16.15 \%$ of the whole population. Among them, 144 million people were over 65 , representing $10.47 \%$ of the whole population.
} 
tool to reflect the state of health of entire populations in one country or region and to evaluate health services and economic cost.

While reflecting the health condition of entire populations in a country or region, the healthy life expectancy is also an index on the distribution of health and the differences in the health among social groups of different socioeconomic statuses. In other words, the healthy life expectancy is an index of health inequality. Previous literature on health inequality primarily relies on single health indices, such as examining mortality inequality or incidents of disease in social groups with different socioeconomic statuses, and they hardly combine disease and mortality into one study. Given that the mortality inequality among different social groups may be distinct from the health inequality among them, the healthy life expectancy has an obvious advantage when measuring the health inequality in one country or region, for it can help to combine and compare mortality and health inequality. Although there are some studies focusing on the inequality of healthy life expectancies among social groups of different socioeconomic statuses, the elderly, especially those at very old age, are seldom included in research samples. Furthermore, most studies are about developed countries or regions, and relevant studies about developing countries are limited. In response to the accelerated population aging in China over the next three decades and the consequent burden on social health services, this paper focuses on the healthy life expectancy of the elderly in China and explores healthy life expectancy inequality among social groups with different socioeconomic statuses.

\section{Literature review}

Since the 1970s, people have shifted their focus from mortality risk (an issue of life expectancy) to chronic disease and daily life functionality (an issue of life quality). The concept and measurement of the healthy life expectancy has thus drawn great interest and attention (Sullivan 1971). The measuring criteria of the healthy life expectancy vary by different health indices. The most popular index of health measurement is the disability-free life expectancy (DFLE) or active life expectancy (ALE). Outside of that, there are self-reported life expectancies (also called healthy life expectancy) and disease-free life expectancy. Compared with single indices for measuring health, the healthy life expectancy can reveal health in the form of both quantity and quality and, moreover, can predict the cost of health services and elderly care. From the social perspective, the healthy life expectancy helps to predict the changes happening in the social participation and integration of senior citizens. Meanwhile, whether the proportion of unhealthy life spans is increased when the lives of patients with chronic diseases are prolonged (Olshansky et al. 1991; Verbrugge 1984), whether this proportion is decreased due to the postponed occurrence of disease (Fries 2003), or whether this proportion is in dynamic balance (Manton 1982), can be evaluated through analysis and the comparison of the healthy life expectancy and life expectancy. Since the healthy life expectancy has advantages for the comprehensive measurement of health, it is often applied in the discussion of health inequality between the sexes, among different social classes and among different countries. The comparison of the healthy life expectancy of different social groups can be used to examine the health institutions of one country or region and to expose influential factors behind health inequality (Pongiglione et al. 2015). 
Existing literature demonstrates that social groups with different socioeconomic statuses are significantly distinct in their healthy life expectancies. In general, social groups with higher socioeconomic status have longer life expectancies and longer healthy life expectancy, and group differences in the healthy life expectancy are larger than their life expectancy differences (Crimmins et al. 1996; Crimmins and Saito 2001; Lievre et al. 2008; Sole-Auro et al. 2015). Studies have found that social groups with lower levels of education have shorter life expectancies and longer life spans under unhealthy conditions than those with higher levels of education. For instance, in Britain, research has found that at the age of 65, the DFLE of the group with the lowest level of education ( $0-9$ years of education) is 1.7 years (for females) and 1.1 years (for males) less than that of the group with the highest level of education (more than 12 years of education), and at the age of 85 , these gaps increase to 2.8 years for females and 2.4 years for males (Jagger et al. 2007). In the USA, some studies have also found that this educational discrepancy is significant in the healthy life expectancy and that this gap is larger than that for life expectancy. It was also discovered that the educational discrepancy increases as time goes on. The reduction in morbidity has already emerged in social groups with relatively high levels of education, while social groups with low levels of education are still suffering from increasing disease incidence (Crimmins and Saito 2001). Domestic studies echo these research findings. One piece of research on the elderly in Beijing showed that at the age of 65, the DFLE of the elderly with relatively high levels of education was 1.44 times (for males) and 1.33 times (for females) the DFLE of the elderly with low levels of education, and at the age of 80, these gaps increased to 1.63 times for males and 1.56 times for females (Kaneda et al. 2005). Moreover, one piece of research on the elderly in Suzhou demonstrated that the proportion of the DFLE in the life expectancy of the elderly with high levels of education was significantly larger than that of the elderly with low levels of education, and this discrepancy increased along with age (Wu and Xu 2011). Separate research conducted in Sao Paulo, Brazil, reflected that along with the improvement of education levels comes a decrease of the proportion of disabled life expectancy in the life expectancy of males and females alike, and with the increasing of age, the proportion of disabled life expectancy increases, though this is not the case for males with high levels of education aged 70-75 years old and 75-80 years old (Camargos et al. 2007).

Existing literature has been devoted to the inequalities in the healthy life expectancy among social groups with different occupations and income levels. It has been proved that the life expectancy of social groups with lower occupational statuses is shorter than that of those with higher occupational statuses. Similarly, their disabled life spans are longer and their disability-free life spans are shorter. For instance, a study of French males found that the life expectancy and the DFLE of management are both longer than that of manual workers, and their disabled life expectancies were shorter. This inequality persisted during the evaluation period of the study (Cambois et al. 2001, 2011). Similarly, research on the elderly in Beijing discovered that at the age of 65, the DFLE of the elderly with high occupational statuses was 1.42 times (for males) and 1.28 times (for females) the DFLE of the elderly with low occupational statuses, and at the age of 80, these gaps increased to 1.61 times for males and 1.35 times for females (Kaneda et al. 2005). In addition, the research shows that income levels have significant influence on the healthy life expectancy of males. At the age of 65 , the healthy life 
expectancy of high-income-level groups is 1.57 times the healthy life expectancy of low-income-level groups; at the age of 80 , this discrepancy increases to 1.77 times. But the healthy life expectancy of high-income-level female groups is not significantly distinct from that of low-income-level female groups (Kaneda et al. 2005). In Brazil, a study showed that the healthy life expectancy of the elderly living in impoverished areas is shorter than that of the elderly living in wealthy areas (Szwarcwald et al. 2016). However, other studies have argued that measuring the socioeconomic statuses of the elderly by their incomes and the occupations has flaws (Kaneda et al. 2005). For example, the influence of income in old age on health may conceal the accumulative effect of lifetime economic status on health. Most senior citizens are retired, and some of the elderly never worked during their lives (such as some women). Thus, occupations and incomes cannot reflect the real socioeconomic statuses of the elderly. In addition, occupations and incomes may be affected by health, and disabilities in early life may result in low occupational statuses, low incomes, or unemployment. Therefore, care should be taken when making conclusions about occupational or income-level discrepancies with regard to health (Matthews et al. 2006).

To explain the inequalities in mortality and health among social groups with different socioeconomic statuses, some theoretical explanations and empirical verifications have been created by previous research. Among them, the theory of fundamental causes suggests that socioeconomic status can affect one or several diseases, as well as health problems, through multiple risk factors (including smoking, excessive sitting, weight gain, pressure, social isolation, preventive medical service, crowded and unsanitary living conditions, unsanitary water, malnutrition, and so on) (Phelan et al. 2010); similarly, the socioeconomic statuses of the individual or social group are closely related to their access to key resources like knowledge, money, power, prestige, advantaged social relations, and so on that can be utilized to avoid risk or reduce disease. The different capabilities of individuals and social groups in possessing and using these resources lead to different coping capabilities and strategies in the case of disease and health. For example, in the case of preventable mortality (e.g., mortality caused by lung cancer), the health inequality derived from socioeconomic status is significant; while in the case of unpreventable mortality or death with unknown causes, the relation of socioeconomic status and health is weak, suggesting different capacities for using resources by social groups with different socioeconomic statuses. Furthermore, some research has tried to explain health inequalities in old age from the perspective of life course (Wadsworth 1997), arguing that the health of adults is partially determined by biological and social factors in their early stages of life. Health inequality is rooted in inequalities in the uterus, childhood, and puberty. Meanwhile, separate research has emphasized the social selection mechanism, suggesting that the so-called health inequality is the consequence of social selection. Health affects people's attainment of socioeconomic status, rather than socioeconomic status affecting health. The health problem leads to downward social mobility, though people with good health, which can be determined by individual characteristics such as the recognition of individual characters, can achieve upward social mobility (West 1991). There has been some research trying to explain this from the perspective of social psychology, believing that social groups with different socioeconomic statuses face different psychological and social pressures, where social groups with low socioeconomic statuses face heavier psychological pressures, a greater sense of 
social deprivation, and less sense of control-factors that are closely related to a series of health problems (Wilkinson 2005). Some work has explained this from the perspective of cultural capital and lifestyles (Abel 2008), pointing out that differences in attitude, knowledge, and capacity among social groups with different socioeconomic statuses result in the differences in disease-related consumption. To show their relatively high socioeconomic status, social groups with high social status may practice lifestyles conducive to health. As social distinctions based on health-related behavior are increasing, health inequality caused by different lifestyles may increase. Last but not least, some research has tried to explain this from the perspective of technology diffusion and has proposed that new medical interventions or technologies be first adopted by social groups with high socioeconomic statuses and then diffused to low socioeconomic groups, which leads to considerable health inequalities in the early stages of medical intervention or improvement (Glied and Lleras-Muney 2008; Victora et al. 2000).

This literature review has helped us to find that most research about inequalities in the healthy life expectancy focus on developed countries in Europe and North America. There is limited research about the elderly healthy life expectancy in China, and such research is based on subjects concentrated in metropolises, such as Beijing and Suzhou (Tang Zhe et al. 2004, 2005; Wu and Xu 2011). Although few studies use nationally representative samples (Peng and Qiang 2006), they adopt population sample survey data at a single point in time and thus cannot calculate the exact probability of the changes in health, which may have led to biased healthy life expectancies. Although other studies explore the changes in health at old age by using follow-up survey data (Qiang and Zhe 2002), these papers do not calculate the healthy life expectancy with reasonable control variables. Furthermore, previous research pays limited attention to the developing trend of inequality in healthy life expectancy and trends of different cohorts and at different ages. The cohort effects and age effects have not been distinguished even though some research has examined the changing trends at different ages. Given drastic population aging and social transitions in China, it is worthwhile to portray the changing trends of health inequality at different periods of time and at different ages, so as to provide academic evidence for relevant policymaking.

Based on this rationale, this paper tries to explore the inequality in healthy life expectancy of the elderly with different socioeconomic statuses by using multi-state models and national long-term follow-up survey data. This paper will also examine the changing trends of inequality in healthy life expectancy at different ages among the elderly born in different cohorts and the elderly born in the same cohorts. Specifically, this paper tries to answer these questions: (1) after controlling other variables, do the elderly of different socioeconomic statuses have different healthy life expectancies or not? Is the inequality in life expectancy the same as the inequality in healthy life expectancy for the elderly of different socioeconomic statuses? (2) For the elderly born in different cohorts, do significant differences exist in the inequalities in healthy life expectancy or not? Compared with the elderly born in early cohorts, are the elderly born in later cohorts undergoing increasing inequalities in healthy life expectancy? (3) As they get older, how will the inequalities in healthy life expectancy among the elderly with different socioeconomic statuses change? After 80 , will the inequalities in healthy life expectancy among the elderly with different socioeconomic statuses diminish? 


\section{Methods}

Data

The data set of this paper is extracted from the Chinese Longitudinal Healthy Longevity Survey (CLHLS) conducted by the center for health and family research on aging at Peking University. The baseline survey of CLHLS was conducted in 1998, followed by tracking studies in 2000, 2002, 2005, 2008, and 2011. ${ }^{2}$ The CLHLS baseline survey and follow-up survey have covered 23 provinces, municipalities, and autonomous regions, in which $85 \%$ of the national population live. This paper extracts the elderly born between 1900 and 1945 (with ages ranging from 61 to 108) as its research sample. After dropping unqualified samples, ${ }^{3}$ a sample of 36,997 people with 82,037 observations is produced. The general information of the baseline survey is listed in Table 1.

\section{Variables and measurements}

Given that previous research primarily chose the activity of daily living (ADL) as the index for health (Pongiglione et al. 2015), this paper follows this approach. Every survey in CLHLS has collected information on six subjects related to their activity of daily living, including having baths, getting dressed, indoor activity, using the bathroom, eating, controlled defecation, and urinating. This paper chooses five of them. ${ }^{4}$ The elderly who are completely independent on these five subjects are categorized as ADL complete, and the elderly who are not completely independent on any subject (relying on other people or equipment) are considered as ADL disabled. Through this approach, we categorize the health condition of the elderly into three groups: healthy (that is ADL complete, labeled as 1), ADL disabled (labeled as 2), and deceased (labeled as 3).

Level of education is one valid index of the socioeconomic status of the elderly (Crimmins et al. 1997; Jagger et al. 2007) because one's level of education is achieved during one's early years and remains unchanged for most people. This paper divides the level of education of the elderly into three groups: the uneducated (coded as 1), people with 1-5 years of education (coded as 2), and people with more than 6 years of education (coded as 3). Furthermore, one's place of residence is often deployed as an index of socioeconomic status of the elderly in China (Zhu and Xie 2007), and thus this paper labels two groups of residence: rural areas (coded as 1) and urban areas (coded as 2). The independent variables of this paper also include age, cohort, sex, and so on. Age is a time-varying variable, ranging from 61 to 108 . The model estimation is centered $^{5}$ at the age of 85 . The birth year of interviewees indicates their cohort, ranging from 1900 to 1945 . The model estimation is centered on the year of 1915. Male interviewees are coded as 0 and females are coded as 1 . The measurement of variables and the distribution information of the sample are shown in Table 2.

\footnotetext{
${ }^{2}$ To ensure the continuity and comparability of various points in time of the tracking survey, deceased interviewees were replaced with new participants of the same sex and same age in the 2000, 2002, 2005, and 2008 follow-up surveys. In the sixth follow-up survey in 2011, deceased interviewees were replaced with new participants only in a few regions.

${ }^{3}$ Unqualified samples refer to samples falling outside of the specified age range, missing values, or having wrong values for some variables.

"After excluding the subject of "controlled defecation and urinating," the Cronbach $\alpha$ of the ADL scale is 0.91; when including the subject of "controlled defecation and urinating," the Cronbach $\alpha$ of the ADL scale is 0.89. Therefore, this paper excludes information on "controlled defecation and urinating."

${ }^{5}$ Centering is a mathematical transition of the original value to improve the estimation and explanation of model coefficients. It is necessary to clarify that the centering of a variable will not affect the estimates produced by the model.
} 
Table 1 Samples of the baseline survey and follow-up information

\begin{tabular}{|c|c|c|c|c|c|c|}
\hline \multirow{2}{*}{$\begin{array}{l}\text { Tracking } \\
\text { year }\end{array}$} & \multirow[t]{2}{*}{ State } & \multicolumn{5}{|l|}{ Baseline years } \\
\hline & & $1998(N=5990)$ & $2000(N=5429)$ & $2002(N=9126)$ & $2005(N=7322)$ & $2008(N=9130)$ \\
\hline \multirow[t]{3}{*}{2000} & Surviving & 3690 & & & & \\
\hline & Deceased & 1690 & & & & \\
\hline & Missing & 610 & & & & \\
\hline \multirow[t]{3}{*}{2002} & Surviving & 2198 & 3275 & & & \\
\hline & Deceased & 1040 & 1335 & & & \\
\hline & Missing & 452 & 819 & & & \\
\hline \multirow[t]{3}{*}{2005} & Surviving & 961 & 1478 & 5376 & & \\
\hline & Deceased & 988 & 1420 & 2524 & & \\
\hline & Missing & 249 & 377 & 1226 & & \\
\hline \multirow[t]{3}{*}{2008} & Surviving & 337 & 575 & 3205 & 3247 & \\
\hline & Deceased & 423 & 627 & 1241 & 2615 & \\
\hline & Missing & 201 & 276 & 930 & 1460 & \\
\hline \multirow[t]{3}{*}{2011} & Surviving & 119 & 227 & 2080 & 1629 & 4045 \\
\hline & Deceased & 164 & 268 & 706 & 1049 & 3328 \\
\hline & Missing & 54 & 80 & 419 & 569 & 1757 \\
\hline
\end{tabular}

\section{Analytical method}

We fit a multi-state model in continuous time (see Fig. 1) to the survey data. The model has three states: ADL complete, ADL disabled, and deceased. The individual state at the time point $t$ is $s(t)$. The arrows in Fig. 1 suggest that a transition between two states is possible. For every pair of states $r$ and $s$, individual transitions from one

Table 2 The measurement of variables and the distribution information of the sample

\begin{tabular}{llll}
\hline Variable & Measurement & Sample & Percentage \\
\hline Sex & Male & 15,974 & 43.18 \\
Female & 21,023 & 56.82 \\
& $1900-1909$ & 12,876 & 34.8 \\
& $1910-1919$ & 12,457 & 33.67 \\
& $1920-1929$ & 6154 & 16.63 \\
Age & $1930-1939$ & 4378 & 11.83 \\
& $1940-1945$ & 1132 & 3.06 \\
& $61-69$ & 3799 & 10.27 \\
Place of residence & $70-79$ & 4656 & 12.58 \\
& $80-89$ & 11,308 & 30.56 \\
Education level & $90-99$ & 11,038 & 29.83 \\
& $100-108$ & 6196 & 16.75 \\
& Urban area & 16,096 & 43.51 \\
Activity of daily living (ADL) & Rural area & 20,901 & 56.49 \\
& Uneducated & 23,406 & 63.26 \\
& $1-5$ years of school & 8243 & 22.28 \\
& 6 years or more of school & 5348 & 14.46 \\
& No disability & 27,785 & 75.1 \\
& Disabled & 9212 & 24.9 \\
\hline
\end{tabular}




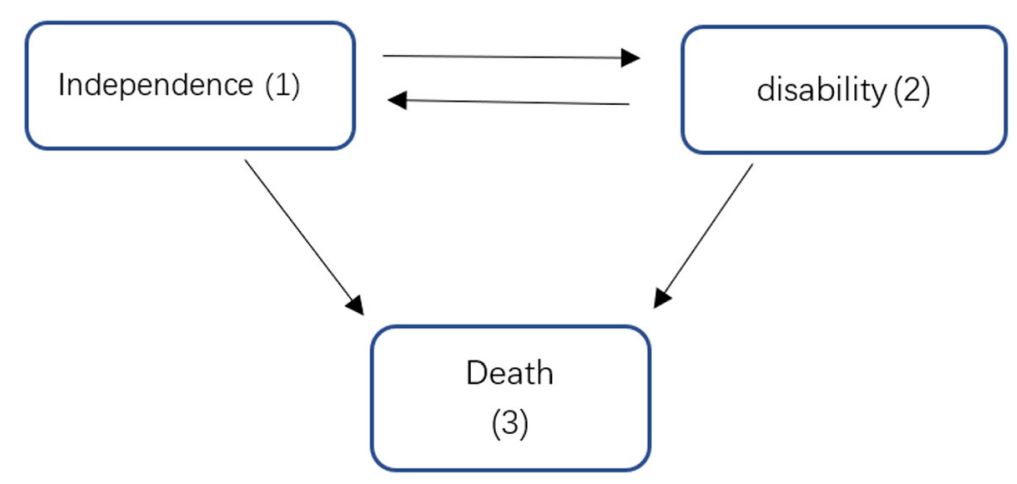

Fig. 1 Multi-state model

state to the other and the times of transition are determined by transition intensities (also called transition hazards) $q_{\mathrm{rs}}(t)$. The transition intensities refer to instantaneous intensities from state $r$ to state $s$ that may be related to the time process $t$ or a set of concomitant variables $x(t)$. The transition intensities can be shown by the following equation:

$$
q_{\mathrm{rs}}(t)=q_{\mathrm{rs}}(t \mid x(t))=q_{\mathrm{rs} .0}(t) \exp \left(\beta_{\mathrm{rs}} x(t)\right) .
$$

In the model, the parameter vector $\beta_{\mathrm{rs}}=\left(\beta_{\mathrm{rs} .1}, \beta_{\mathrm{rs} .2}, \ldots, \beta_{\mathrm{rs} . \mathrm{p}}\right)$ and the covariance vector $x(t)=\left(x_{1}(t), x_{2}(t), \ldots, x_{p}(t)\right), q_{\text {rs.o }}(t)$ indicate baseline risk.

First, this paper builds an intercept-only model that supposes that the function for baseline time risk fits an exponential distribution and that the time-dependent effect and covariance vector effect do not exist:

$$
\left.q_{\mathrm{rs}}(t)=q_{\mathrm{rs}}=\exp \left(\beta_{\mathrm{rs}}\right) \text { (the intercept-only model }\right)
$$

Second, this paper builds a model (Model 1) with a time-dependent effect by assuming that the function of baseline risk fits a Gompertz distribution:

$$
q_{\mathrm{rs}}(t)=\exp \left(\beta_{\mathrm{rs} .0}+\xi_{\mathrm{rs}} t\right)(\text { Model } 1)
$$

Since this paper uses the age (in years) as a measurement of time, $t$ stands for age. The introduction of related covariates into Model 1 aims at examining the effect of covariates:

$$
\begin{aligned}
& q_{\mathrm{rs}}(t)=\exp \left(\beta_{\mathrm{rs} .0}+\xi_{\mathrm{rs}} \text { age }+\beta_{\mathrm{rs} .1} \operatorname{cohort}+\beta_{\mathrm{rs} .2} \text { sex }+\beta_{\mathrm{rs} .3} \text { residence }\right) \text { (Model 2) } \\
& q_{\mathrm{rs}}(t)=\exp \left(\beta_{\mathrm{rs} .0}+\xi_{\mathrm{rs}} \text { age }+\beta_{\mathrm{rs} .1} \operatorname{cohort}+\beta_{\mathrm{rs} .2} \operatorname{sex}+\beta_{\mathrm{rs} .3} \text { education }\right)(\text { Model 3) }
\end{aligned}
$$

We use the maximum likelihood method to estimate the matrix of transition intensities in these models above. We also make a model comparison through the maximum value of the likelihood function and AIC. By calculating the matrix of transition probabilities from the matrix of transition intensities, the duration of stay at each state is achieved, such as the duration of stay in ADL complete (healthy life expectancy) and in ADL disabled (unhealthy life expectancy). For instance, using age as the measurement of time, the calculation of the duration of stay in terms of age at the state $s$ under the original state $r$ is as follows: 


$$
e_{\mathrm{rs}}\left(t_{1}\right)=e_{\mathrm{rs}}\left(t_{1} \mid x\left(t_{1}\right)\right)=\int_{0}^{\infty} P\left(Y_{\mathrm{t} 1+u}=s \mid Y_{\mathrm{t} 1}=r, x\left(t_{1}\right)\right) d u
$$

In this equation, $P\left(Y_{\mathrm{t} 1+\mathrm{u}}=s \mid Y_{\mathrm{t} 1}=r, x\left(t_{1}\right)\right)$ refers to the transition probability at the state $s$ and the age $t_{1+\mathrm{u}}$ when the original state is $r$ at the age $t_{1}$. The matrix of transition intensities can achieve the matrix of transition probabilities through the calculation of the multi-state model. The equation below can obtain the entire duration under healthy or unhealthy conditions regardless of the original state (excluding the state of death):

$$
e_{. s}\left(t_{1}\right)=\sum e_{\mathrm{rs}}\left(t_{1}\right) P\left(Y_{\mathrm{t} 1}=r \mid x\left(t_{1}\right)\right)
$$

Therefore, the expected duration under healthy conditions (or unhealthy conditions) - that is, the healthy life expectancy (or the disabled life expectancy) - is the sum of the expected duration under healthy conditions (or disabled conditions) with different original states. To calculate the healthy life expectancy or disabled life expectancy, we also need to know the probability distribution of every original state at the age $t_{1}$, which can be achieved by an independent logistic regression model. The total life expectancy in terms of age is as follows:

$$
e\left(t_{1}\right)=\sum e_{. s}\left(t_{1}\right)
$$

This paper uses the msm package in $\mathrm{R}$ to estimate the multi-state model (Jackson 2011), and it uses the ELECT package in R to calculate life expectancy and healthy life expectancy. ${ }^{6}$

\section{Results}

\section{Socioeconomic status and transitions in health}

Table 3 shows the three models' estimates for transition intensities. It can be seen that as one gets older, the probabilities of transitioning from a healthy condition to a disabled condition, from a healthy condition to death and from a disabled condition to death all increase significantly in the three models, while the transition probability from the disabled condition to the healthy condition decrease significantly. Table 3 also shows that cohorts have a significant influence on the transition between the healthy condition and the disabled condition given that the probability of the transition from health to disability for the elderly in late cohorts is relatively low and that the probability of the transition from health to death is low as well. There is not, however, a significant difference in the transition from disability to death for the elderly in different cohorts in Table 3. Moreover, the female elderly have a significantly higher probability for the transition from health to disability than that of the male elderly, but they also have a significantly lower probability for the transition from health to death and from disability to death than that of the male elderly.

Table 3 demonstrates that although there is no significant difference in the probability for the transition from health to disability between the elderly in rural areas and the elderly in urban areas, Model 2 shows that the elderly in rural areas have a higher probability for the transition from health to death than their urban counterparts.

${ }^{6}$ Van den Hout, A. 2016, "ELECT: Estimation of Life Expectancies Using Continuous-TimeMulti-State Survival Models. " ELECT Version 0.2. Vignette. 
Table 3 Estimates of transitional intensities of the multi-state model

\begin{tabular}{|c|c|c|c|c|c|c|c|}
\hline \multirow[b]{2}{*}{ Variable } & \multirow[b]{2}{*}{ Transition } & \multicolumn{2}{|l|}{ Model 1} & \multicolumn{2}{|l|}{ Model 2} & \multicolumn{2}{|l|}{ Model 3} \\
\hline & & Coefficient & SE & Coefficient & SE & Coefficient & SE \\
\hline \multirow[t]{4}{*}{ Baseline } & $q 12$ & $-2.455^{* * *}$ & 0.026 & $-2.311^{* * *}$ & 0.052 & $-2.312^{* * *}$ & 0.059 \\
\hline & $q 13$ & $-3.004^{* * *}$ & 0.026 & $-2.834^{* * *}$ & 0.061 & $-2.643^{* * *}$ & 0.064 \\
\hline & q21 & $-1.487^{* * *}$ & 0.044 & $-1.425^{* * *}$ & 0.089 & $-1.070^{* * *}$ & 0.097 \\
\hline & $\mathrm{q} 23$ & $-1.265^{* * *}$ & 0.027 & $-1.295^{* * *}$ & 0.04 & $-1.168^{* * *}$ & 0.045 \\
\hline \multirow[t]{4}{*}{ Age } & $\mathrm{q} 12$ & $0.079^{* * *}$ & 0.002 & $0.058^{* * *}$ & 0.005 & $0.057^{* * *}$ & 0.005 \\
\hline & $\mathrm{q} 13$ & $0.069^{* * *}$ & 0.002 & $0.060^{* * *}$ & 0.006 & $0.060^{* * *}$ & 0.006 \\
\hline & q21 & $-0.031^{* * *}$ & 0.004 & $-0.074^{* * *}$ & 0.009 & $-0.073^{* * *}$ & 0.009 \\
\hline & $\mathrm{q} 23$ & $0.027^{* * *}$ & 0.002 & $0.035^{* * *}$ & 0.004 & $0.036^{* * *}$ & 0.004 \\
\hline \multirow[t]{4}{*}{ Cohort } & $\mathrm{q} 12$ & & & $-0.021^{* * *}$ & 0.005 & $-0.022^{* * *}$ & 0.005 \\
\hline & $\mathrm{q} 13$ & & & $-0.010^{*}$ & 0.006 & -0.009 & 0.006 \\
\hline & q21 & & & $-0.041^{* * *}$ & 0.008 & $-0.038^{* * *}$ & 0.008 \\
\hline & $\mathrm{q} 23$ & & & 0.005 & 0.004 & 0.006 & 0.004 \\
\hline \multirow[t]{4}{*}{ Female } & $\mathrm{q} 12$ & & & $0.121^{* * *}$ & 0.037 & $0.106^{* *}$ & 0.042 \\
\hline & $\mathrm{q} 13$ & & & $-0.347^{* * *}$ & 0.042 & $-0.430^{* * *}$ & 0.046 \\
\hline & q21 & & & 0.041 & 0.061 & -0.044 & 0.069 \\
\hline & $\mathrm{q} 23$ & & & $-0.215^{* * *}$ & 0.026 & $-0.239 * * *$ & 0.029 \\
\hline \multirow[t]{4}{*}{ Rural area } & $\mathrm{q} 12$ & & & -0.037 & 0.035 & & \\
\hline & $\mathrm{q} 13$ & & & $0.107^{* * *}$ & 0.042 & & \\
\hline & q21 & & & $0.446^{* * *}$ & 0.059 & & \\
\hline & $\mathrm{q} 23$ & & & $0.185^{* * *}$ & 0.024 & & \\
\hline \multirow[t]{4}{*}{$1-5$ years of education } & $q 12$ & & & & & -0.053 & 0.048 \\
\hline & $\mathrm{q} 13$ & & & & & $-0.118^{* *}$ & 0.051 \\
\hline & q21 & & & & & $-0.167^{* *}$ & 0.080 \\
\hline & $\mathrm{q} 23$ & & & & & -0.023 & 0.035 \\
\hline \multirow[t]{4}{*}{6 years or more of education } & $\mathrm{q} 12$ & & & & & -0.042 & 0.058 \\
\hline & $\mathrm{q} 13$ & & & & & $-0.310^{* * *}$ & 0.067 \\
\hline & q21 & & & & & $-0.343^{* * *}$ & 0.099 \\
\hline & $\mathrm{q} 23$ & & & & & $-0.173^{* * *}$ & 0.044 \\
\hline
\end{tabular}

Notes: (1) $* p<0.1, * * p<0.05, * * * p<0.01$. (2) q12 refers to the transition from ADL complete to ADL disabled; $\mathrm{q} 13$ refers to the transition from ADL complete to deceased; q21 refers to the transition from ADL disabled to ADL complete; q23 refers to the transition from ADL disabled to deceased

Furthermore, the elderly in rural areas have significantly higher probabilities for the transitions from disability to health and from disability to death than their urban counterparts. Model 3 in Table 3 shows that although there is no significant difference in the probability for the transition from health to disability among the elderly with different education backgrounds, significant differences exist in the probability for the transition from disability to health. The probability for the transition from disability to health decreases along with the increase of years of education. Meanwhile, there are significant differences in the probability for mortality among the elderly with different educational backgrounds. The probability of transition from health to death decreases along with the increase of years of education. In the case of the transition from disability to death, there is no significant difference between the elderly with 1-5 years of education and the uneducated elderly; the same probability for the elderly with 6 years or more of education is significantly lower than that of the uneducated elderly. 
The life expectancy and healthy life expectancy of the elderly at different places of residence

Table 4 shows the total life expectancy and healthy life expectancy of the elderly living in different areas, born in different cohorts and at different ages. As we anticipated, life expectancy and healthy life expectancy decrease with increasing age. Table 4 also demonstrates how the life expectancy of the elderly in urban areas is longer than that of those in rural areas for both females and males. As age increases, however, the discrepancy in life expectancy between urban and rural males

Table 4 Life expectancy and healthy life expectancy in different areas, in different cohorts, and at different ages

\begin{tabular}{|c|c|c|c|c|c|c|c|c|}
\hline \multirow[t]{3}{*}{$\overline{\text { Age }}$} & \multicolumn{4}{|c|}{ Female } & \multicolumn{4}{|l|}{ Male } \\
\hline & \multicolumn{2}{|l|}{ Rural } & \multicolumn{2}{|l|}{ Urban } & \multicolumn{2}{|l|}{ Rural } & \multicolumn{2}{|l|}{ Urban } \\
\hline & $\overline{\mathrm{HLE}}$ & LE & $\overline{\mathrm{HLE}}$ & LE & $\overline{\mathrm{HLE}}$ & LE & $\overline{\mathrm{HLE}}$ & LE \\
\hline \multicolumn{9}{|c|}{1940 cohort } \\
\hline 65 & 14.77 & 16.47 & 14.42 & 16.65 & 13.57 & 14.74 & 13.47 & 15.06 \\
\hline 70 & 11.73 & 13.39 & 11.38 & 13.58 & 10.81 & 11.95 & 10.71 & 12.24 \\
\hline 72 & 10.64 & 12.27 & 10.30 & 12.46 & 9.82 & 10.94 & 9.71 & 11.22 \\
\hline \multicolumn{9}{|c|}{1930 cohort } \\
\hline 72 & 10.10 & 11.80 & 9.68 & 11.95 & 9.24 & 10.41 & 9.07 & 10.66 \\
\hline 75 & 8.56 & 10.25 & 8.16 & 10.39 & 7.87 & 9.03 & 7.70 & 9.27 \\
\hline 78 & 7.19 & 8.84 & 6.83 & 8.98 & 6.65 & 7.78 & 6.48 & 8.01 \\
\hline 79 & 6.77 & 8.41 & 6.41 & 8.55 & 6.28 & 7.40 & 6.11 & 7.62 \\
\hline 80 & 6.37 & 7.99 & 6.01 & 8.12 & 5.93 & 7.03 & 5.75 & 7.24 \\
\hline 81 & 5.99 & 7.58 & 5.64 & 7.72 & 5.58 & 6.68 & 5.40 & 6.88 \\
\hline 82 & 5.63 & 7.19 & 5.28 & 7.33 & 5.25 & 6.34 & 5.08 & 6.53 \\
\hline \multicolumn{9}{|c|}{1920 cohort } \\
\hline 78 & 6.82 & 8.52 & 6.37 & 8.64 & 6.22 & 7.40 & 5.99 & 7.60 \\
\hline 79 & 6.39 & 8.08 & 5.95 & 8.21 & 5.85 & 7.03 & 5.62 & 7.22 \\
\hline 80 & 5.98 & 7.66 & 5.56 & 7.79 & 5.49 & 6.66 & 5.27 & 6.86 \\
\hline 81 & 5.60 & 7.27 & 5.18 & 7.40 & 5.16 & 6.32 & 4.93 & 6.50 \\
\hline 82 & 5.23 & 6.88 & 4.83 & 7.01 & 4.83 & 5.98 & 4.61 & 6.16 \\
\hline 85 & 4.22 & 5.82 & 3.86 & 5.96 & 3.95 & 5.07 & 3.74 & 5.23 \\
\hline 88 & 3.37 & 4.91 & 3.04 & 5.05 & 3.20 & 4.27 & 3.00 & 4.42 \\
\hline 89 & 3.12 & 4.63 & 2.80 & 4.77 & 2.97 & 4.03 & 2.77 & 4.18 \\
\hline 90 & 2.88 & 4.37 & 2.57 & 4.51 & 2.75 & 3.80 & 2.56 & 3.95 \\
\hline 91 & 2.65 & 4.12 & 2.35 & 4.26 & 2.55 & 3.58 & 2.36 & 3.72 \\
\hline 92 & 2.44 & 3.89 & 2.15 & 4.02 & 2.36 & 3.38 & 2.18 & 3.51 \\
\hline \multicolumn{9}{|c|}{1910 cohort } \\
\hline 88 & 3.11 & 4.72 & 2.75 & 4.87 & 2.90 & 4.04 & 2.68 & 4.21 \\
\hline 89 & 2.85 & 4.45 & 2.51 & 4.61 & 2.68 & 3.81 & 2.46 & 3.97 \\
\hline 90 & 2.62 & 4.19 & 2.29 & 4.35 & 2.47 & 3.58 & 2.26 & 3.75 \\
\hline 91 & 2.40 & 3.95 & 2.09 & 4.11 & 2.28 & 3.38 & 2.08 & 3.54 \\
\hline 92 & 2.19 & 3.72 & 1.90 & 3.89 & 2.10 & 3.18 & 1.90 & 3.34 \\
\hline 95 & 1.66 & 3.11 & 1.40 & 3.28 & 1.62 & 2.65 & 1.44 & 2.80 \\
\hline 100 & 1.00 & 2.30 & 0.82 & 2.49 & 1.01 & 1.94 & 0.87 & 2.10 \\
\hline
\end{tabular}

Note: HLE stands for healthy life expectancy and LE stands for life expectancy, as below 
decreases, while the discrepancy between urban and rural females decreases at first and then increases. Figure 2 shows how different cohorts of the Chinese elderly have significantly different life expectancies. At the age of 72, the rural-urban gap of the 1940s cohort is larger than that of the 1930s cohort. Similarly, between the ages of 78 and 82, the rural-urban gap of the 1930s cohort is larger than that of the 1920s cohort. Between the ages of 88 and 92, however, the rural-urban gap of the 1920s cohort is smaller than that of the 1910s cohort. In this sense, since 1920, the rural-urban gap in life expectancy between the elderly in late cohorts and those in early cohorts has increased while ages remain controlled.

Although the life expectancy of the elderly in urban areas is longer than that of the elderly in rural areas, the latter have longer healthy life expectancies than their urban counterparts. Figure 2, however, shows that as age increases, the rural-urban discrepancy in healthy life expectancy increases at first and then decreases. Furthermore, the rural-urban discrepancy in healthy life expectancy shows significant differences among different cohorts given that, at the same age, the rural-urban discrepancy in healthy life expectancy is relatively small in late cohorts. Figure 2 also shows how the healthy life expectancy of the elderly in rural areas is $2 \%$ to $12 \%$ higher than that of the elderly in urban areas. As age increases, the rural preponderance in healthy life expectancy increases. The proportion of healthy life expectancy within total life expectancy for the elderly of rural and urban areas is significantly different within different cohorts. Also, the rural-urban discrepancy in the proportion of healthy life expectancy for late cohorts is relatively small.

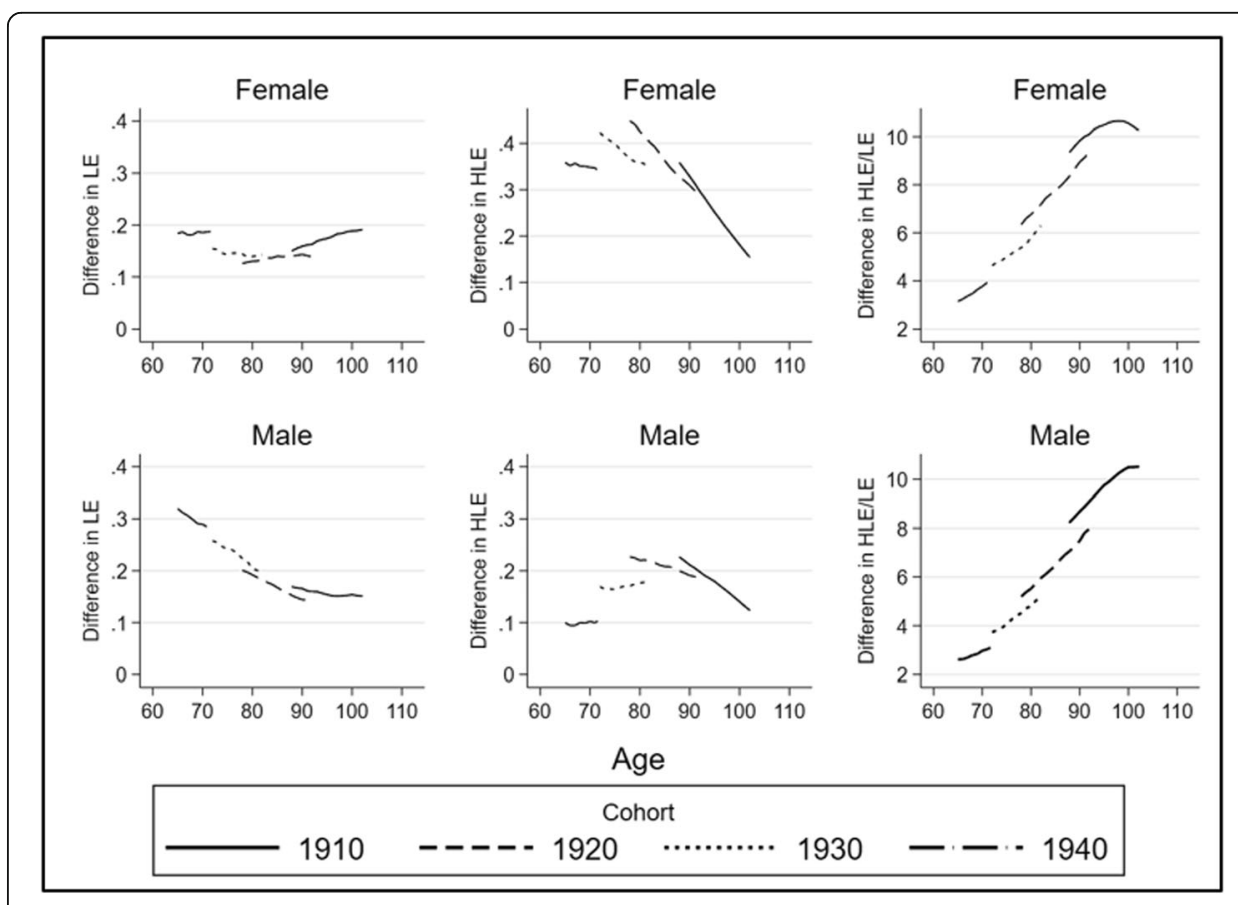

Note: urban > rural in LE; rural > urban in HLE; rural > urban in HLE/LE

Fig. 2 The rural-urban gap in life expectancy and healthy life expectancy in different cohorts and at different ages 
The life expectancy and healthy life expectancy of the elderly with different education backgrounds

Table 5 shows the life expectancy and healthy life expectancy for the elderly with different education backgrounds, born in different cohorts, and at different ages. First, elderly individuals with different education backgrounds have significantly different life expectancies given that their life expectancies increase along with increases in education level. Figure 3 calculates the discrepancy in life expectancy between the elderly with 6 years or more of education (highly educated) and the uneducated elderly (little education). As age increases, the gap in life expectancy of old people with different

Table 5 The life expectancy and healthy life expectancy for different education backgrounds, in different cohorts, and at different ages

\begin{tabular}{|c|c|c|c|c|c|c|c|c|c|c|c|c|}
\hline \multirow[t]{3}{*}{ Age } & \multicolumn{6}{|c|}{ Female } & \multicolumn{6}{|l|}{ Male } \\
\hline & \multicolumn{2}{|c|}{ Uneducated } & \multicolumn{2}{|c|}{$1-5$ years } & \multicolumn{2}{|c|}{6 years or more } & \multicolumn{2}{|c|}{ Uneducated } & \multicolumn{2}{|c|}{$1-5$ years } & \multicolumn{2}{|c|}{6 years or more } \\
\hline & $\overline{H L E}$ & LE & $\overline{\mathrm{HLE}}$ & LE & $\overline{\mathrm{HLE}}$ & LE & $\overline{\mathrm{HLE}}$ & LE & $\overline{\mathrm{HLE}}$ & LE & $\overline{\mathrm{HLE}}$ & $\mathrm{LE}$ \\
\hline \multicolumn{13}{|c|}{1940 cohort } \\
\hline 65 & 14.47 & 16.27 & 14.94 & 16.83 & 15.37 & 17.74 & 12.96 & 14.10 & 13.51 & 14.76 & 14.18 & 15.75 \\
\hline 70 & 11.50 & 13.25 & 11.90 & 13.77 & 12.26 & 14.53 & 10.30 & 11.42 & 10.79 & 12.01 & 11.34 & 12.86 \\
\hline 72 & 10.42 & 12.14 & 10.81 & 12.65 & 11.12 & 13.37 & 9.34 & 10.45 & 9.80 & 11.01 & 10.32 & 11.81 \\
\hline \multicolumn{13}{|c|}{1930 cohort } \\
\hline 72 & 9.83 & 11.68 & 10.15 & 12.11 & 10.41 & 12.85 & 8.79 & 9.98 & 9.17 & 10.46 & 9.63 & 11.26 \\
\hline 75 & 8.34 & 10.15 & 8.63 & 10.55 & 8.84 & 11.22 & 7.48 & 8.65 & 7.84 & 9.09 & 8.22 & 9.81 \\
\hline 78 & 7.01 & 8.77 & 7.27 & 9.13 & 7.44 & 9.74 & 6.31 & 7.45 & 6.64 & 7.87 & 6.96 & 8.49 \\
\hline 79 & 6.60 & 8.34 & 6.85 & 8.69 & 7.00 & 9.27 & 5.96 & 7.08 & 6.27 & 7.49 & 6.57 & 8.09 \\
\hline 80 & 6.21 & 7.93 & 6.45 & 8.27 & 6.58 & 8.82 & 5.62 & 6.73 & 5.92 & 7.12 & 6.20 & 7.70 \\
\hline 81 & 5.83 & 7.53 & 6.07 & 7.86 & 6.19 & 8.39 & 5.29 & 6.39 & 5.58 & 6.77 & 5.84 & 7.32 \\
\hline 82 & 5.47 & 7.15 & 5.70 & 7.47 & 5.81 & 7.98 & 4.98 & 6.06 & 5.26 & 6.42 & 5.50 & 6.96 \\
\hline \multicolumn{13}{|c|}{1920 cohort } \\
\hline 78 & 6.58 & 8.45 & 6.77 & 8.77 & 6.91 & 9.37 & 5.88 & 7.10 & 6.15 & 7.46 & 6.44 & 8.10 \\
\hline 79 & 6.16 & 8.02 & 6.35 & 8.33 & 6.47 & 8.91 & 5.53 & 6.74 & 5.79 & 7.09 & 6.05 & 7.70 \\
\hline 80 & 5.77 & 7.61 & 5.95 & 7.91 & 6.05 & 8.47 & 5.19 & 6.39 & 5.44 & 6.73 & 5.68 & 7.31 \\
\hline 81 & 5.39 & 7.22 & 5.57 & 7.50 & 5.65 & 8.05 & 4.86 & 6.06 & 5.11 & 6.39 & 5.33 & 6.94 \\
\hline 82 & 5.03 & 6.84 & 5.20 & 7.12 & 5.28 & 7.64 & 4.55 & 5.74 & 4.79 & 6.06 & 4.99 & 6.59 \\
\hline 85 & 4.06 & 5.81 & 4.21 & 6.05 & 4.26 & 6.51 & 3.72 & 4.87 & 3.92 & 5.15 & 4.07 & 5.61 \\
\hline 88 & 3.23 & 4.90 & 3.37 & 5.12 & 3.38 & 5.53 & 3.01 & 4.10 & 3.18 & 4.35 & 3.28 & 4.75 \\
\hline 89 & 2.99 & 4.63 & 3.12 & 4.84 & 3.12 & 5.23 & 2.79 & 3.87 & 2.96 & 4.11 & 3.05 & 4.49 \\
\hline 90 & 2.76 & 4.37 & 2.88 & 4.57 & 2.87 & 4.94 & 2.59 & 3.66 & 2.75 & 3.88 & 2.83 & 4.25 \\
\hline 91 & 2.54 & 4.13 & 2.66 & 4.32 & 2.64 & 4.67 & 2.40 & 3.45 & 2.55 & 3.66 & 2.61 & 4.01 \\
\hline 92 & 2.34 & 3.89 & 2.45 & 4.07 & 2.43 & 4.41 & 2.22 & 3.25 & 2.36 & 3.45 & 2.42 & 3.79 \\
\hline \multicolumn{13}{|c|}{1910 cohort } \\
\hline 88 & 2.94 & 4.73 & 3.03 & 4.92 & 3.02 & 5.34 & 2.71 & 3.90 & 2.84 & 4.12 & 2.92 & 4.53 \\
\hline 89 & 2.70 & 4.47 & 2.79 & 4.65 & 2.77 & 5.05 & 2.50 & 3.68 & 2.63 & 3.88 & 2.70 & 4.28 \\
\hline 90 & 2.47 & 4.21 & 2.56 & 4.39 & 2.53 & 4.77 & 2.30 & 3.47 & 2.43 & 3.66 & 2.48 & 4.04 \\
\hline 91 & 2.26 & 3.97 & 2.34 & 4.14 & 2.31 & 4.51 & 2.12 & 3.27 & 2.24 & 3.45 & 2.28 & 3.81 \\
\hline 92 & 2.07 & 3.75 & 2.14 & 3.91 & 2.11 & 4.26 & 1.95 & 3.08 & 2.06 & 3.25 & 2.10 & 3.60 \\
\hline 95 & 1.56 & 3.14 & 1.62 & 3.28 & 1.58 & 3.60 & 1.50 & 2.57 & 1.59 & 2.72 & 1.60 & 3.02 \\
\hline 100 & 0.93 & 2.35 & 0.98 & 2.45 & 0.94 & 2.72 & 0.93 & 1.91 & 0.99 & 2.02 & 0.99 & 2.26 \\
\hline
\end{tabular}


education backgrounds narrows. At the same age, the gap in life expectancy between high levels of education and low levels of education is significantly different among different cohorts. This educational discrepancy in life expectancy is relatively large in late cohorts.

Second, the elderly with high levels of education have significant advantages in healthy life expectancy. As Table 5 shows, the healthy life expectancy of the elderly increases along with the increase of their education level. Table 3 shows that, however, as they get older, the discrepancy of the healthy life expectancy of the elderly with different education backgrounds decreases. Table 3 also demonstrates that the gap in healthy life expectancy between the elderly with high levels of education (6 years or more of education) and the uneducated elderly is narrower than their gap in life expectancy. Meanwhile, the educational inequality in healthy life expectancy is affected by the cohort given that, at the same age, the educational gap in healthy life expectancy in late cohorts is larger than that in early cohorts. Figure 3 shows that the proportion of healthy life expectancy within the total life span for the elderly with low levels of education is $2 \%$ to $6 \%$ higher than that for old people with high levels of education. As age increases, the gap in the proportion of healthy life expectancy within the total life span increases for old people with different education backgrounds. In addition, the gaps in the proportion of healthy life expectancy between individuals with low levels of education and those with high levels of education are different among different cohorts. At the same age, the gaps in the proportion of healthy life expectancy among the elderly with different education backgrounds is relatively small in late cohorts.

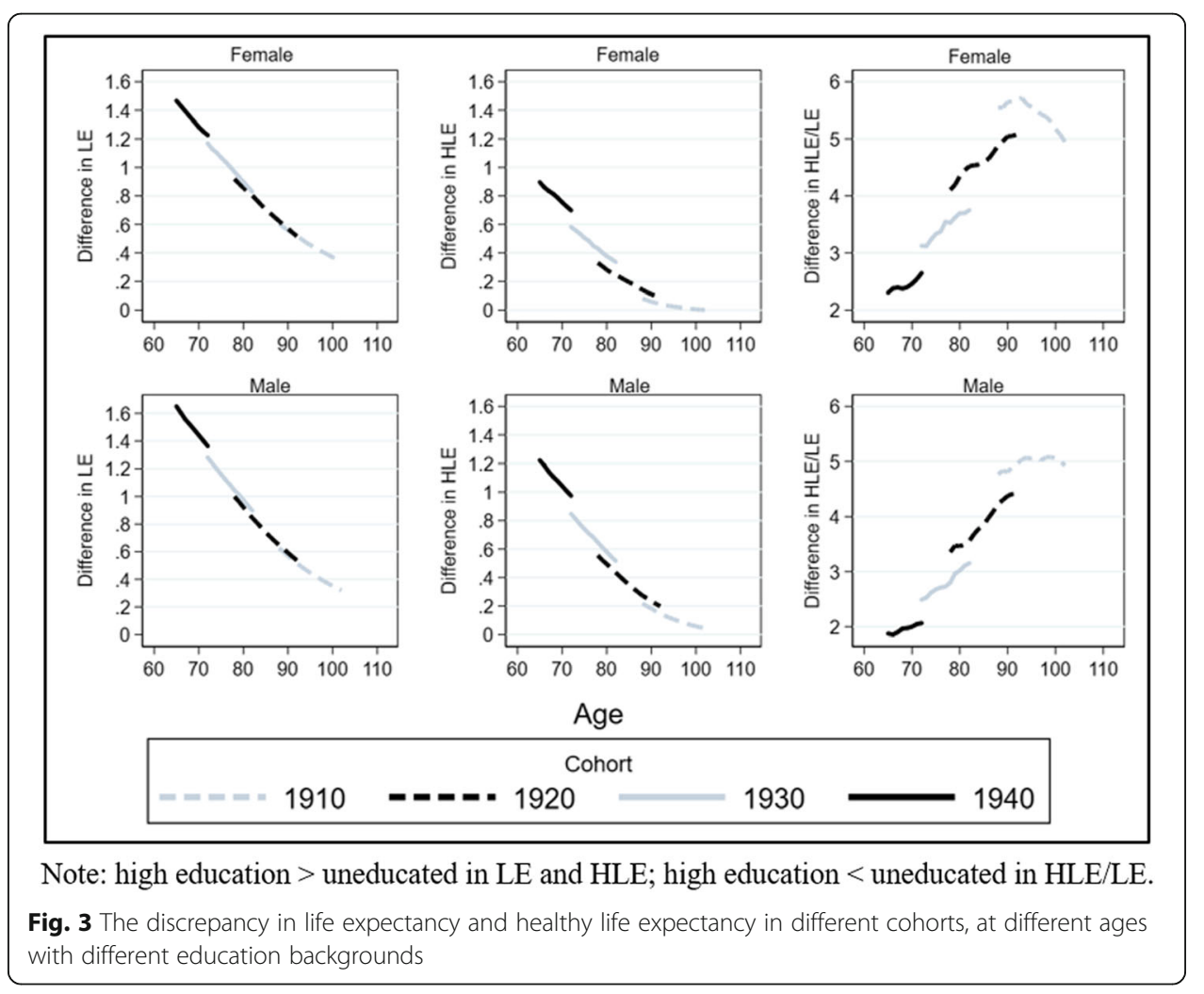




\section{Conclusion and discussion}

With a multi-state model and data derived from a national 13-year longitudinal survey, this paper tries to explore the transition between health conditions of the Chinese elderly and, based on this exploration, discover inequalities in the life expectancy and the healthy life expectancy among elderly with different socioeconomic statuses. Compared with existing studies about health inequality in old age that generally deploy single indices (such as mortality or incidence rate of disease), this paper uses a comprehensive measuring index-the healthy life expectancy-to explore the health and health inequality of the elderly in China from a broad perspective. Furthermore, this paper includes a large number of elderly as its research sample, which helps us to study health inequality throughout the entirety of old age from a comprehensive perspective while also discovering the different influences of socioeconomic status on the health of the elderly at different ages. In addition, this paper fills the gap in previous research where the age effect and cohort effect were not made distinct through the exploration of the transitions in health inequality of the elderly at different ages and the transitions among different cohorts. Furthermore, unlike previous research that used Sullivan's approach (Sullivan 1971), this paper adopts a multi-state model of continuous time points that can estimate and compare the health transition probabilities and the life expectancies of different subgroups (categorized by sex, age, place of residence, and level of education), in order to specifically reveal health inequality among the elderly and, to some extent, offset the estimation bias due to sample reduction. ${ }^{7}$ This paper finds that there is no significant difference in the incidence rate of disability (the transition from health to disability) between the elderly in rural areas and the elderly in urban areas, yet the rural elderly have significantly higher rates of recovery (from disability to health) than their urban counterparts. These findings are inconsistent with what have been found in developed Western countries, where most research suggests that the incidence rate of disability of social groups with relatively low socioeconomic status is higher than that of social groups with high socioeconomic status (Jagger et al. 2007). Differences among social groups with respect to the rate of recovery have not been found in most research (Yong and Saito 2012). In China, the elderly in rural areas do not underperform in their incidence rate of disability but do outperform in their recovery rate, which may be related to the following factors. (1) A social selection mechanism based on health: as shown in this paper, the elderly in rural areas have higher transition rates from disability to death than their urban counterparts, which means that the surviving elderly in rural areas either have disabilities of low severity or better physical endowments that allow them to often outperform in the recovery from their disabilities. On the contrary, with good health services and living conditions, the elderly in urban areas have relatively low rates of mortality even though they suffer from serious disabilities. People with serious disabilities and poor physical endowments may thus survive in urban areas, though they usually underperform in the recovery from their disabilities. (2) The elderly in rural areas often live with poorly maintained facilities (such as washrooms,

${ }^{7}$ It is necessary to take into account the influence of mortality when discussing the health of the elderly, especially for those in very old age. If a research sample was collected at one time point, such a sample would be formed by rather healthy people. In this sense, overestimation possibly exists during the estimation of life expectancy and healthy life expectancy based on single-time-point data. The use of longitudinal data can, to some extent, reduce this sample selection bias. 
laundry facilities, cooking facilities, bathing facilities, and drinking water) that force them to take care of themselves with limited assistance from domestic facilities, not to mention that most old people in rural areas live in single-story houses and engage in many outdoor activities, all of which results in their strong ability to care for themselves throughout their daily lives. Even with similar states of health and functioning organs, the elderly in rural areas have better abilities to care for themselves in their daily lives and more optimistic attitudes in reporting on their ability to care for themselves than their counterparts living in urban areas. This may lead to the relatively low incidence rates for disability in the empirical study.

In addition, this paper shows that there is no significant gap within the incidence rate of disability among old people with different levels of education, though the disability recovery rate for the less educated elderly is higher than that of the well-educated, which is also inconsistent with research findings from developed Western countries. This is related to the factors discussed in the last paragraph. In a word, the inequality of the incidence rate of disability among social groups with different socioeconomic status, which is widely found in the Western world, has not yet emerged in China (Fuller et al. 2009; von dem Knesebeck et al. 2003). This is probably because the childhoods of China's elderly, especially the very old, occurred during an historical period of long-lasting wars, and their adulthoods were spent during a period of planned economic systems and collectivisms after the founding of the People's Republic of China and before the reform and opening up. Despite social stratification to some extent, most social groups have experienced relative equality in which socioeconomic backgrounds, such as education, have not played a key role in individual attainment of social resources or medical services, and they have had a relatively low influence on health. Consequently, the elderly with relatively high socioeconomic statuses have not accumulated advantages in health since the primes of their lives, and they have had no significantly lowered incidence rates for certain chronic disability-causing diseases compared to their counterparts with low socioeconomic status.

This paper demonstrates, however, that the inequality in mortality (including the transition from healthy to deceased and the transition from disabled to deceased) is significant. The elderly in rural areas have a higher risk of mortality than the elderly in urban areas, and the less educated elderly have a higher risk of mortality than those who are well-educated, which is consistent with most existing studies (Mackenbach et al. 2008). With respect to the inequality in mortality among old people with different socioeconomic statuses, we can explain this from several aspects. (1) With economic development and fundamental health care development, the major causes of mortality have already shifted from acute and epidemic diseases to chronic and mental disease. The incidence, treatment and recovery of the latter causes are significantly related to material resources, sanitary conditions, lifestyles, social relationships, and the knowledge of health possessed by individuals and social groups. (2) Due to their limited material resources as well as their relatively unhealthy lifestyles, the elderly with low socioeconomic statuses, who are often less educated or live in rural areas, have a relatively high incidence rate for chronic and lethal diseases (Howard et al. 2000; Steenland et al. 2002), especially for preventable lethal diseases (Masters et al. 2015). (3) Suffering from the same chronic and lethal diseases, or similar disabilities, the elderly with less education and who live in rural areas are impacted by the quantity and quality of 
accessible care services, medical technology, and services (Kapral et al. 2002). On the contrary, the elderly with high levels of education or who live in urban areas can make use of their access to medical services to slow down the progression of diseases and reduce the mortality risks of certain lethal diseases.

Furthermore, this paper examines the healthy life expectancy and its inequalities among the elderly at different places of residence and with different levels of education. It is found that the life expectancy of the elderly in rural areas is shorter than that of the elderly in urban areas, but the rural elderly have a longer healthy life expectancy, which is known as the "rural-urban paradox" and has been observed in some studies conducted in China. There are several possible causes of the "rural-urban paradox." (1) According to the multi-state model in this paper, the span of the healthy life expectancy can be broken into two parts: first is the healthy life expectancy under original conditions of health multiplied by the probability of such conditions ${ }^{8}$; second is the healthy life expectancy after the transition from disabled to healthy multiplied by the probability of being originally disabled. (2) The rural elderly stay in a state of health longer than the urban elderly. The rural elderly have a higher probability of remaining healthy than their urban counterparts, which results in the rural elderly having a longer healthy life expectancy under original conditions of health than the elderly in urban areas. Moreover, the rural elderly outperform their urban counterparts in the transition from disability to health and thus have a longer healthy life expectancy after the transition to disability. These two factors lead to a longer total healthy life expectancy of the elderly in rural areas than that of the elderly in urban areas. (3) Due to their better recovery rate from disability and high mortality risk when disabled, the rural elderly have a shorter life expectancy than their urban counterparts after their transition from being healthy to disabled. They also have a shorter life expectancy when disabled and when their original condition is one of disability. In sum, the rural elderly live for relatively shorter durations in the condition of disability than their urban counterparts. On the contrary, in urban areas, good medical conditions and living environments protect the disabled elderly who would otherwise have relatively high mortality risks, and this prolongs their total life spans when disabled. (4) Since the rural-urban gap in the unhealthy or disabled life expectancy among old people is larger than the rural-urban gap in healthy life expectancy, the total life expectancy of the urban elderly is longer than that of the rural elderly, and the healthy life expectancy of the urban elderly is shorter than that of the rural elderly.

This paper also finds that the life expectancy and healthy life expectancy have a consistent trend among the elderly with different education levels: the less educated elderly have both a shorter life expectancy and a shorter healthy life expectancy compared to the well-educated elderly. But the healthy life expectancy of the less-educated elderly constitutes a greater proportion of the total life expectancy than that of the welleducated elderly, which is inconsistent with what is found in China (Wu and Xu 2011; Kaneda et al. 2005). The possible cause for this is that existing research is primarily based on data cross-sections at a single point of time or follow-up data for a short period of time, leading to biased conclusions. Several explanations can be formed to

${ }^{8}$ By using an independent logistic regression model $(1=$ healthy, $0=$ disability $)$, we can calculate the probabilities of health and disability for every group of elderly during each year. 
decode the findings of this paper. (1) When the original condition is health, the welleducated elderly have a longer healthy life expectancy compared to the less-educated elderly; when the original condition is one of disability, the well-educated elderly have a shorter life expectancy after the transition from disability to health compared to their less-educated counterparts. Well-educated people, however, still enjoy a longer total healthy life expectancy than less-educated people. (2) Similar to the rural-urban inequality in the unhealthy/disabled life expectancy, the well-educated elderly have a longer life expectancy after the transition from health to disability than the less-educated elderly due to their low recovery rate and low mortality risk under the condition of disability. When the original condition is disability, the well-educated elderly have a longer life expectancy in the condition of disability compared to the less-educated elderly, ultimately leading to their longer total life expectancy in the condition of disability. This reflects how the inequality in total life expectancy among old people with different levels of education is made up by the gap in healthy life expectancy and the gap in the unhealthy/disabled life expectancy. (3) Due to their relatively long healthy life expectancy and their unhealthy/disabled life expectancy, the well-educated elderly in general have a longer total life expectancy than their less-educated counterparts. The healthy life expectancy of the urban elderly occupies less of their total life expectancy than that of the rural elderly, and the healthy life expectancy of the well-educated elderly occupies a smaller proportion of their total life expectancy than that of less-educated people. This shows how the elderly with higher socioeconomic statuses are not experiencing the reduction in disabilities seen in Western societies (Crimmins and Saito 2001; Fries 2002). Instead, they are seeing increased disability.

Furthermore, this paper makes clear the age effect and the cohort effect. We discover that with respect to the life expectancy of the elderly, either rural-urban inequality or discrepancies among different education levels reduce along with the increase of age. The rural-urban inequality in the healthy life expectancy increases, however, at first and then decreases with age, while the inequality in the healthy life expectancy among the elderly with different levels of education consistently falls with age. In sum, the inequality in total life expectancy and the healthy life expectancy among the elderly with different socioeconomic statuses is decreasing with age, which is generally consistent with the research findings of the relevant studies (Huisman et al. 2003). It is worth noting that the discrepancy in the life expectancy among the elderly with different socioeconomic statuses does not disappear with age, though it does decrease as people get very old. This is also true when people reach the age of 95 or above. This indicates that both the incidence rate of disability and mortality increase significantly with age, and biological factors and individual physical endowments have greater influence on health than external socioeconomic factors, resulting in a tendency for the decreasing influence of socioeconomic factors. Moreover, with their aging and the considerable increase in mortality, the elderly with relatively low socioeconomic statuses can survive under the high rate of mortality and demonstrate their good physical endowments. On the contrary, the elderly with relatively high socioeconomic statuses can survive with the help of external socioeconomic conditions, even with poor physical endowments. Therefore, the physical endowments of the elderly with low socioeconomic statuses is probably better than that of the elderly with high socioeconomic statuses as they get very old, and thus the inequality in life expectancy and healthy life expectancy will 
decrease. Meanwhile, this paper finds that the elderly in rural areas and the lesseducated elderly have a greater proportion of healthy life expectancy in their total life expectancy than their urban and well-educated counterparts, a tendency that increases with age. This finding also demonstrates that the urban elderly and well-educated elderly spend a greater proportion of their life expectancy in an unhealthy/disabled state than their rural and less-educated counterparts, a tendency that increases with age. As people get very old, good socioeconomic conditions can prolong life spans under the disabled condition. In other words, an increasing of disability has emerged in the group of elderly with high socioeconomic statuses, and this is even more severe in the group of the oldest senior citizens.

This paper also finds that the elderly in late cohorts have a longer life expectancy and a longer healthy life expectancy than those in early cohorts at the same age, which indicates that the people's general health has improved with the development of society and the passing of time. All social groups have enjoyed this improvement no matter their different socioeconomic statuses, but they differ in degree. Generally speaking, the improvement of the urban elderly has been to a greater degree than that of the rural elderly, and the improvement of the welleducated elderly has been to a greater degree than that of the less-educated elderly. In other words, this paper reveals that the rural-urban inequality in life expectancy of the elderly increases with the advancing of the year of birth, and the ruralurban inequality in healthy life expectancy has decreased since the 1920s cohort. For life expectancy and healthy life expectancy, education inequality has enlarged with the advancing of the year of birth. These findings prove that health inequality among social groups with different socioeconomic statuses is increasing in the later cohorts (Lynch 2003). One of the major causes of this may be that social groups with different socioeconomic statuses are enjoying unequal health-related welfare from the development of society and the economy. Social groups with relatively high socioeconomic statuses can enjoy the health improvements brought by the development of society, medicine, and technology through easy access at an early stage. As society, medicine, and technology in China continue to progress, social groups with different socioeconomic statuses may undergo increasingly serious health inequalities in the future, and we should be aware of this and deal with the relevant countermeasures.

Finally, this paper has several limits. (1) This paper uses the basic activities of daily life as a health index to calculate the healthy life expectancy, also known as the active daily life expectancy. With a different health index, the calculated healthy life expectancy may be different. Whether the findings of this paper are applicable in describing the healthy life expectancy calculated by other health indices (such as the selfestimated healthy life expectancy, the disease-free life expectancy, or the no-cognitiveimpairment life expectancy) - and whether the elderly with different socioeconomic statuses are different in terms of healthy life expectancy inequality-needs further discussion. (2) This paper uses the rural-urban index and education background as the measurement for socioeconomic status. Although previous studies agree that education better represents elderly socioeconomic status as opposed to occupation and income, it is worth further discussion whether health inequality among the elderly would be different if a different index, such as those based on financial assets and housing, were 
used to estimate socioeconomic status. (3) Although this paper distinguishes the age effect and cohort effect by examining health inequality among the elderly in different cohorts and at different ages, it only compares the conditions of four cohorts at several points of age due to the limited time scale of the longitudinal survey data. The difference among each cohort at different age points could be discussed if the longitudinal survey data with a longer time scale were available in the future.

Acknowledgements

Gratitude goes to National Social Sciences Research Funds (No. 14 BRK012).

Authors' contributions

$\mathrm{KJ}$ collected the data and drafted the manuscript. The author read and approved the final manuscript.

Funding

This work was supported by the National Social Sciences Research Funds (No. 14 BRK012).

\section{Availability of data and materials}

The datasets used and/or analyzed during the current study are available from the corresponding author on reasonable request.

Competing interests

The author declares that he/she has no competing interests.

Received: 7 July 2019 Accepted: 5 November 2019

Published online: 21 November 2019

\section{References}

Abel, Thomas. 2008. Cultural Capital and Social Inequality in Health. Journal of Epidemiology and Community Health. 62 (7): e13-e13.

Camargos, M.C.S., C.J. Machado, and R.D. Rodrigues. 2007. Disability Life Expectancy for the Elderly, City of Sao Paulo, Brazil, 2000: Gender and Educational Differences. Journal of Biosocial Science. 39 (3): 455-463.

Cambois, Emmanuelle, Caroline Laborde, Isabelle Romieu, and Jean Marie Robine. 2011. Occupational Inequalities in Health Expectancies in France in the Early 2000s: Unequal Chances of Reaching and Living Retirement in Good Health. Demographic Research. 25 (12): 407-436.

Cambois, Emmanuelle, Jean Marie Robine, and Mark D. Hayward. 2001. Social Inequalities in Disability-Free Life Expectancy in the French Male Population, 1980-1991. Demography. 38 (4): 513-524.

Crimmins, E.M., Y. Saito, and D. Ingegneri. 1997. Trends in Disability-Free Life Expectancy in the United States, 1970-90. Population and Development Review. 23 (3): 555-572.

Crimmins, Eileen M., Mark D. Hayward, and Yasuhiko Saito. 1996. Differentials in Active Life Expectancy in the Older Population of the United States. The Journals of Gerontology Series B: Psychological Sciences and Social Sciences. 51 (3): S111-S120.

Crimmins, Eileen M., and Yasuhiko Saito. 2001. Trends in Healthy Life Expectancy in the United States, 1970-1990: Gender, Racial, and Educational Differences. Social Science and Medicine 52 (11): 1629-1641.

Fries, James F. 1983. The Compression of Morbidity. The Milbank Memorial Fund Quarterly. 61 (3): 397-419.

Fries, James F. 2002. Aging, Natural Death, and the Compression of Morbidity. Bulletin of the World Health Organization. 80 (3): $245-250$.

Fries, James F. 2003. Measuring and Monitoring Success in Compressing Morbidity. Annals of Internal Medicine. 139 (5): 455-459.

Fuller, Thomson, E.A. Nuru, Jeter M. Minkler, and J.M. Guralnik. 2009. Black-White Disparities in Disability among Older Americans Further Untangling the Role of Race and Socioeconomic Status. Journal of Aging and Health. 21 (5): 677-698.

Glied, Sherry, and Adriana Lleras-Muney. 2008. Technological Innovation and Inequality in Health. Demography 45 (3): 741-761.

Howard, G., R.T. Anderson, G. Russell, V.J. Howard, and G.L. Burke. 2000. Race, Socioeconomic Status, and Cause-Specific Mortality. Annals of Epidemiology. 10 (4): 214-223.

Huisman, Martijn, Anton E. Kunst, and Johan P. Mackenbach. 2003. Socioeconomic Inequalities in Morbidity among the Elderly: A European Overview. Social Science and Medicine. 57 (5): 861-873.

Jackson, C.H. 2011. Multi-State Models for Panel Data: The Msm Pachage for R. Journal of Statistical Software. 38 (8): 1-29.

Jagger, C., R. Matthews, D. Melzer, F. Matthews, and C. Brayne. 2007. Educational Differences in the Dynamics of Disability Incidence, Recovery and Mortality: Findings from the MRC Cognitive Function and Ageing Study (MRC CFAS). International Journal of Epidemiology. 36 (2): 408-414.

Kaneda, Toshiko, Zachary Zimmer, and Zhe Tang. 2005. Socioeconomic Status Differentials in Life and Active Life Expectancy among Older Adults in Beijing. Disability and Rehabilitation. 27 (5): 241-251.

Kapral, Moira K., Hua Wang, Muhammad Mamdani, and Jack V. Tu. 2002. Effect of Socioeconomic Status on Treatment and Mortality After Stroke. Stroke. 33 (1): 268-275.

Lievre, A., D. Alley, and E.M. Crimmins. 2008. Educational Differentials in Life Expectancy with Cognitive Impairment among the Elderly in the United States. Journal of Aging and Health. 20 (4): 456-477.

Lynch, Scott M. 2003. Cohort and Life-Course Patterns in the Relationship between Education and Health: A Hierarchical Approach. Demography. 40 (2): 309-331. 
Mackenbach, J.P., I. Stirbu, A.J. Roskam, M.M. Schaap, G. Menvielle, M. Leinsalu, and A.E. Kunst. 2008. Socioeconomic Inequalities in Health in 22 European Countries. New England Journal of Medicine. 358 (23): 2468-2481.

Manton, Kenneth G. 1982. Changing Concepts of Morbidity and Mortality in the Elderly Population. The Milbank Memorial Fund Quarterly. 60 (2): 183-244.

Masters, Ryan K., Bruce G. Link, and Jo C. Phelan. 2015. Trends in Education Gradients of 'Preventable' Mortality: A Test of Fundamental Cause Theory. Social Science and Medicine. 127: 19-28.

Matthews, R.J., C. Jagger, and R.M. Hancock. 2006. Does Socio-economic Advantage Lead to a Longer, Healthier Old Age? Social Science and Medicine. 62 (10): 2489-2499.

Olshansky, S. Jay, Mark A. Rudberg, Bruce A. Carnes, Christine K. Cassel, and Jacob A. Brody. 1991. Trading Off Longer Life for Worsening Health: The Expansion of Morbidity Hypothesis. Journal of Aging and Health 3 (2): 194-216.

Peng, Du, and Li Qiang. 2006. Disability-free Life Expectancy of Chinese Elderly and its Change between 1994 and 2004. Population Research. 5: 9-16.

Phelan, Jo C., Bruce G. Link, and Parisa Tehranifar. 2010. Social Conditions as Fundamental Causes of Health Inequalities: Theory, Evidence, and Policy Implications. Journal of Health and Social Behavior. 51 (1): S28-S40.

Pongiglione, B., B.L. De Stavola, and G.B. Ploubidis. 2015. A Systematic Literature Review of Studies Analyzing Inequalities in Health Expectancy among the Older Population. Plos One 10 (6): e0130747.

Qiang, Li, and Tang Zhe. 2002. The Application of Multivariate Multistate Life Table in Analysis of The Healthy Life Expectancy of Old People in China. Population Science of China. 6: 40-48.

Sole-Auro, A., H. Beltran-Sanchez, and E.M. Crimmins. 2015. Are Differences in Disability-Free Life Expectancy by Gender, Race, and Education Widening at Older Ages? Population Research and Policy Review. 34 (1): 61-70.

Steenland, Kyle, Jane Henley, and Michael J. Thun. 2002. All-Cause and Cause-specific Death Rates by Educational Status for Two Million People in Two American Cancer Society Cohorts, 1959-1996. American Journal of Epidemiology. 156 (1): 11-21.

Sullivan, Daniel F. 1971. A Single Index of Mortality and Morbidity. HSMHA Health Report. 86 (4): 347-354.

Szwarcwald, C.L., P.R.B. de Souza, A.P. Marques, W.D. de Almeida, and D.E.R. Montilla. 2016. Inequalities in Healthy Life Expectancy by Brazilian Geographic Regions: Findings from the National Health Survey, 2013. International Journal for Equity in Health. 15: 141

Verbrugge, L.M. 1984. Longer Life but Worsening Health? Trends in Health and Mortality of Middle-Aged and Older Persons. Milbank Memorial Fund Quarterly 62 (3): 475-519.

Victora, Cesar G., J. Patrick Vaughan, Fernando C. Barros, Anamaria C. Silva, and Elaine Tomasi. 2000. Explaining Trends in Inequities: Evidence from Brazilian Child Health Studies. The Lancet. 356 (9235): 1093-1098.

von dem Knesebeck, O., G. Luschen, W.C. Cockerham, and J. Siegrist. 2003. Socioeconomic Status and Health Among the Aged in the United States and Germany: A Comparative Cross-Sectional Study. Social Science and Medicine. 57 (9): 1643-1652.

Wadsworth, M.E.J. 1997. Health Inequalities in the Life Course Perspective. Social Science and Medicine. 44 (6): 859-869.

West, Patrick. 1991. Rethinking the Health Selection Explanation for Health Inequalities. Social Science and Medicine. 32 (4): 373-384.

Wilkinson, Richard G. 2005. The Impact of Inequality: How to Make Sick Societies Healthier. New York: The New Press.

Wu, Yan, and Yong Xu. 2011. Studying the activity life expectancy of the elderly with different social-economic statuses. Chinese Health Service Management. 8: 625-627.

Yong, V., and Y. Saito. 2012. Are There Education Differentials in Disability and Mortality Transitions and Active Life Expectancy Among Japanese Older Adults? Findings from a 10-Year Prospective Cohort Study. Journals of Gerontology Series B: Psychological Sciences and Social Sciences. 67 (3): 343-353.

Zhe, Tang, Xiang Manjun, and Fang Xianghua. 2004. Life and Active Life Expectancy of Elderly People with Different Socioeconomic Status in Beijing. Chinese Journal of Clinical Rehabilitation. 30: 6569-6571.

Zhe, Tang, Xiang Man-jun, Zachary Zimmer, Fang Xiang-hua, and Toshiko Kaneda. 2005. Study on the Active Life Expectancy of the Elderly and Its Longitudinal Transition in Beijing. Chinese Journal of Epidemiology. 12: 939-942.

Zhu, H.Y., and Y. Xie. 2007. Socioeconomic Differentials in Mortality Among the Oldest of the Old in China. Research on Aging. 29 (2): $125-143$.

\section{Publisher's Note}

Springer Nature remains neutral with regard to jurisdictional claims in published maps and institutional affiliations.

\section{Submit your manuscript to a SpringerOpen ${ }^{\circ}$ journal and benefit from:}

- Convenient online submission

- Rigorous peer review

- Open access: articles freely available online

- High visibility within the field

- Retaining the copyright to your article

Submit your next manuscript at $\boldsymbol{\nabla}$ springeropen.com 